\title{
Outlook of Pharmacoeconomics and its status in Nepal
}

\author{
Sabita Paudel \\ Department of Pharmacology, Gandaki Medical College, Pokhara, Nepal
}

\section{Correspondence}

Dr. Sabita Paudel

Department of Pharmacology, Gandaki Medical College,

Pokhara, Nepal

\section{Email:}

drsabitapaudel@gmail.com

DOI: http://dx.doi.org/10.3126/ jcmsn.v14i1.19503

Orcid ID: orcid.org/0000-0001 $-9462-8007$

Article received: Dec $10^{\text {th }} 17$

Article accepted: Mar $6^{\text {th }} 2018$

\begin{abstract}
Pharmacoeconomics is a branch of health economics which is derived from latin word "Pharmacon"- and "Economia"- It deals with the economic aspect of health that is the costs of health services. There are different types of costs which is affecting the health services. There is not only the direct medical cost, but also direct nonmedical cost, indirect nonmedical costs and intangible cost. The consequences of therapy are evaluated from economic, clinical and humanistic perspective, also known as the ECHO model. There are partial and full pharmacoeconomic analyses. The partial analyses are cost of illness and cost of consequence. The full analyses are cost effective, cost benefit, cost utility and cost minimization analyses. The cost effective analysis is the most commonly used analysis
\end{abstract}

Key words: Cost; ECHO model; pharmacoeconomic analyses

Citation: Paudel S. Outlook of Pharmacoeconomics and its status in Nepal. JCMS Nepal. 2018;14(1):56-8.

\section{INTRODUCTION}

Pharmacoeconomics (PE) deals with the economic aspect of health. This topic is new in Nepal. It is just in its inception. There is not much work done in this field. It is a branch of health economics. We extremely lack the pharmacoeconomic analyses of drugs in our country. ${ }^{1}$ The policy of the country doesn't mandate the compulsory pharmacoeconomic analysis of newer drug treatment or procedure. This is one of the reasons why we are lagging and not much developed in the field.

Pharmacoeconomics is new to the world too and was developed in 1970s. McGhan, Rowland \& Bootman in the University of Minnesota pointed out concepts of cost-benefit \& cost-effectiveness analyses in 1978. The term Pharmacoeconomics was first published in 1986 by Townsend. ${ }^{2}$ There are different types of costs- direct medical, direct nonmedical, indirect nonmedical and intangible.

\section{Direct Medical Cost}

This is the cost that is directly involved with the treatment like the cost of medicine, medical supplies, diagnostic tests, etc. The charges of the bed in the hospital is also included in this type.

\section{Direct Nonmedical Cost}

This is the costs that is not directly associated with medicine and medical supplies. The cost of transportation to and fro the health center, special diets, visits to the emergency department, extra hospital visits are included in this type of costs.

\section{Indirect Nonmedical Cost}

This is the cost that is lost due to the absenteeism from the work or loss of productivity due to the illness.

\section{Intangible cost}

The pain, suffering, grief of the patients and caregivers is included in this type. This type of costs is usually excluded while forming the insurance policies.

\section{Consequence (ECHO model) $)^{3-7}$}

Consequence is defined as the effects, outputs, or outcomes of program or drug therapy. 
a. Economic outcomes - It compares different types of costs like direct, indirect, and intangible costs with consequences of medical treatment alternatives.

b. Clinical outcomes - The medical events that occur due to disease or treatment is the clinical outcome.

c. Humanistic outcomes - It is the holistic approach. This outcome measures the mental, social and spiritual well being of the patient. It quantifies whether the patients health condition is restored as that of before illness or not.

\section{Evaluation}

There are different perspectives of evaluation. The out of poccket expense of the patient not covered by insurance is the patient perspective. The provider perspective is the services provided by the institutions like hospitals which is also the direct cost. The cost covered by insurance companies, employers or the government is the payer perspective. All direct and indirect costs also comes under social perspective.

\section{Pharmacoeconomic analyses}

The partial analyses are cost of illness and cost consequence. The full analyses are cost effective (CEA), cost benefit (CBA), cost utility (CUA) and cost minimization analyses (CMA).

\section{Cost effective analysis}

The most commonly employed analysis is the CEA. It measures effectiveness in natural units like decrease in uric acid level, decrease in blood glucose and the costs in money. The therapies with qualitatively similar outcomes is compared. The average cost-effectiveness ratio (ACER) or an incremental cost effectiveness ratio (ICER) is used to compare the treatment alternatives.

ACER $=$ Net Cost $/$ Net Health Benefit

ICER $=$ Cost of drug A - Cost of drug B / Benefits of drug $\mathrm{A}-$ Benefits of drug $\mathrm{B}$

$=$ Difference in costs $(A-B) /$ Difference in benefits (A-B)

The countries like Australia, New Zealand, and Canada have incorporated this analysis in their policies. $^{4-12}$

\section{Cost minimization analysis}

This analysis measures the outcome only in terms of monetary value. This is the difference from cost effective analysis where outcome is measured in terms of natural units. While comparing the two treatment alternatives, the one with the low direct medical cost is selected. The cost that is included here are the costs directly related to medicine like medicine preparation, nursing care, hospital visits, physician consultations, etc. ${ }^{4-13}$

\section{Cost Benefit Analysis}

The costs as well as the benefits of the treatment alternatives are measured and then both are converted into equivalent rupees in the year in which they will occur. The difference with cost minimization analysis is that it also measures benefits. The similarity is that both analyses measures outcome in monetary value. The costs and benefits are expressed as a ratio, a benefit-to-cost (B:C) ratio). It also measures and quantifies direct costs and direct benefits.

\section{Cost utility analysis}

It measures the outcome in terms of health related quality of life. The death is rated zero and the perfect health as one. The perfect health is the state of complete physical, mental, social and spiritual well being of the patient for a year. The quality of life is usually rated between 0 to 1 . If the person is in a complete state of health with medication/ intervention for six months, it becomes 0.5. If the person is not in a complete state of health, lets say 0.5 for five years, it becomes 2.5. This type of analyses is done more frequently in cancer patients. The measurement of quality of life is a holistic approach in the treatment. ${ }^{4-7,14-16}$

\section{Importance of Pharmacoeconomics}

The pharmacoeconomic analyses are very useful in effective formulary management which many countries are now adopting. It is also helpful in individual patient treatment. In many countries, medication policy mandates $\mathrm{PE}$ analyses which is very essential for proper health care management and resource allocation. They have the strong universal health coverage policy. They formulate their reimbursement policies based on pharmacoeconomic analyses of the drugs for the particular treatment. The analyses depends upon the disease and the drugs. There are disease modelling and then budget impact analyses is done. ${ }^{17}$ The cost effective treatment is then chosen and incorporated into the standard treatment guidelines of the country and eventually in the insurance scheme. In our 
country we have national standard treatment guidelines for few diseases, insurance policy is grooming up ${ }^{18}$ and national formulary is also in the process of revision, so its very essential that we include pharmacoeconomic analyses in our drug policy. It also helps in the rational use of medicine.

\section{CONCLUSION}

The field of Pharmacoeconomics is still unexplored in Nepal which has taken up a huge leap in developed countries, as well as in our neighboring countries. There are various types of costs which are quantified and analyses done. The cost effective analysis is the most commonly employed one. The pharmacoeconomic analyses help a lot in forming the standard treatment guidelines and the formulary of the country. Thus it needs to be incorporated in the drug policy of Nepal.

\section{REFERENCES}

1. Lohani S. Initiating pharmacoeconomics and outcomes research in Nepal: Are we ready? 2014. ISPOR Annual Meeting, Montreal Canada.

2. Townsend RJ. Post-marketing drug research and development. Ann Pharmac. 1987;21:134-6.

3. Eisenberg JM. Clinical economics: A guide to economic analysis of clinical practices. JAMA. 1989;262:2879-86. https://doi.org/10.1001/ jama.262.20.2879. PMID: 2509745.

4. Mackinnon GE. Understanding Health Outcomes and Pharmacoeconomics. 15th edi. Portugal: Jones and Bartlett; 2013.

5. Rascati KL. Essentials of Pharmacoeconomics. 2nd edi. Lippincott Williams \& Wilkins. Wolters Kluwer. Philadelphia.

6. Pradelli L, Wertheimer A. Pharmacoeconomics Principles and Practice. SEEd publisher; 2013.

7. Arnold R. Carmen A, editors. Pharmacoeconomics. Boca Raton: CRC Press; 2009.

8. Costa JSD, Fuchs SD, Olinto MTA, Gigante DP, MenezesAMB, Macedo S, et al. Cost-effectiveness of hypertension treatment: a population-based study. Sao Paulo Med. J. 2002;120(4):100-4. https:// doi.org/10.1590/S1516-31802002000400002.

9. Moran AE, Odden MC, Thanataveerat A, Tzong YK, Rasmusen PW, Guzman D et al. Cost-Effectiveness of Hypertension Therapy According to 2014 Guidelines. N Engl J Med. 2015;372:447-55. https:// doi.org/10.1056/NEJMsa1406751. PMID: 25629742.

10. Geroy LS. Economic evaluation for first-line antihypertensive medicines: applications for the Philippines. Cost Eff Resour Alloc. 2012;10(1):14.

11. Johannesson $M$. The cost-effectiveness of the switch towards more expensive antihypertensive drugs. Health Policy. 1994;28:1-13. https:// doi.org/10.1016/0168-8510(94)90016-7

12. Alefan Q, Izham M, Ibrahim M, Razak TA, Ayub A.Cost of treating hypertension in Malaysia. Asian J Pharm Clin Res. 2009;2(1):1-5.

13. Savkar MK, Bhat NP, GD, Shwetha. Evaluation of pharmacoeconomics awareness among post graduates: a questionnaire based study. IJBAMR. 2014;3(3):135-41

14. Tiwari A, Yadav P. Pharmaco - economic study of antidiabetic drugs. Proceedings of 27th IRF International Conference, 24th May 2015, Pune, India.

15. Suleiman IA, Fadeke OF and Okubanjo OO. Pharmacoeconomic Evaluation of Anti-Diabetic Therapy in A Nigerian Tertiary Health Institution. Ann Afr Med. 2006;5(3):132-7.

16. Miravitlles M, Jardim JR, Zitto T, Rodrigues JE, López H. Pharmacoeconomic Study of Antibiotic Therapy for Acute Exacerbations of Chronic Bronchitis and Chronic Obstructive Pulmonary Disease in Latin America. Brazil. Arch Bronconeumol. 2003;39(12):549-53. https:// doi.org/10.1157/13054360. PMID: 14636491.

17. Zwart-van Rijkom JE, Leufkens HG, Busschbach JJ, Broekmans AW, Rutten FF. Differences in Attitudes, Knowledge and Use of Economic Evaluations in Decision-Making in The Netherlands The Dutch Results from the EUROMET Project. Pharmacoeconomics. 2000 Aug;18(2):149-60. PMID: 11067649.

18. Khanal S, Lennert V, Samantha H and Lisa N. Shift in disease burden from communicable to noncommunicable diseases: aiming to achieve Universal Health Coverage in Nepal. Perspect Public Health. 2015;135(4): 177-8. https:// doi.org/10.1177/1757913915586654 PMID: 26148895 